\title{
Características dos componentes externos e das gorduras descartadas de novilhos superprecoces não-castrados ou castrados de dois genótipos terminados em confinamento
}

\section{Jonatas Cattelam ${ }^{1}$, Leandro da Silva Freitas ${ }^{2}$, Ivan Luiz Brondani ${ }^{3}$, José Henrique Souza da Silva $^{3}$, Miguelangelo Ziegler Arboitte ${ }^{4}$, Matheus Smidt Weise ${ }^{5}$}

\footnotetext{
${ }^{1}$ Curso de Medicina Veterinária - UFSM.

2 Doutorando do PPGZ - UFSM. Bolsista REUNI.

${ }^{3}$ Departamento de Zootecnia - UFSM.

${ }^{4}$ Doutorando do PPGZ - UFSM. Bolsista CAPES.

${ }^{5}$ Curso de Zootecnia - UFSM.
}

RESUMO - Objetivou-se com este estudo avaliar as características dos componentes externos e da gordura de descarte de novilhos de duas condições sexuais e dois genótipos terminados em confinamento. A idade e o peso médios dos animais ao início do período experimental foram de 12 meses e 267,0 kg, respectivamente. Os novilhos foram confinados até atingirem o peso de abate pré-estabelecido médio de $400 \mathrm{~kg}$. A dieta foi formulada com relação volumoso:concentrado de 50:50, com base na matéria seca, com $10 \%$ de proteína bruta. O delineamento experimental utilizado foi o inteiramente casualizado, em arranjo fatorial de $2 \times 2$, composto de duas condições sexuais e dois grupos genéticos. O peso de corpo vazio (PCV), os rendimentos de carcaça em relação ao peso de corpo vazio e a relação entre o peso de corpo vazio e o peso de abate foram similares entre genótipos e condições sexuais. Para o peso absoluto das orelhas, observou-se interação significativa entre genótipo e condição sexual dos novilhos. Animais castrados apresentaram maiores valores de gordura intestinal em relação ao peso de corpo vazio (1,62 versus $1,18 \%$ ) e ao peso ao abate (1,41 versus $1,02 \%)$ e de cabeça em relação ao peso ao abate (3,78 versus 3,29\%). Os animais com predominância de sangue Charolês apresentaram maior peso absoluto de vassoura da cauda $(0,16$ versus $0,11 \mathrm{~kg})$ e novilhos Nelore maiores pesos relativos de couro e gordura renal. Não há correlação entre o rendimento de carcaça e os componentes não-integrantes da carcaça.

Palavras-chave: Charolês, condição sexual, couro, Nelore, peso de corpo vazio

\section{Characteristics of external components and discard fat of castrated or non- castrated young steers of different genotypes, feedlot finished}

\begin{abstract}
The objective of this study was to evaluate the characteristics of external components and discard fat of young steers with two different sexual conditions and two different genotypes, finished in feedlot. Average age and weight of the animals at the beginning of the experimental period were 12 months and $267.0 \mathrm{~kg}$, respectively. The steers were in feedlot until reaching pre-established slaughter weight of $400 \mathrm{~kg}$. Diet contained roughage:concentrate ratio of 50:50, on dry matter basis, with $10 \%$ crude protein. It was used a complete randomized experimental design, in a $2 \times 2$ factorial arrangement, composed of two sexual conditions and two genetic groups. Empty body weight (EBW), carcass dressing in relation to empty body weight and the relationship between empty body weight and slaughter weight were similar among genotypes and sexual conditions. For absolute weight of ears, it was observed significant interaction between genotypes and sexual conditions of steers. Castrated animals showed greater values of intestinal fat in relation to empty body weight (1.62 versus $1.18 \%)$. Animals with Charolais predominance showed greater absolute values to tail broom (0.16 versus $0.11 \mathrm{~kg})$ and Nellore steers predominance presented greater weight related to rawhide and renal fat. There is no correlation among carcass dressing and non-integrant components of carcass.
\end{abstract}

Key Words: Charolais, empty body weight, Nellore, rawhide, sexual condition

\section{Introdução}

Junto com a valorização da carne bovina, tem-se dado ênfase ao estudo dos componentes não-integrantes da carcaça. Isto ocorre em consequência da valorização dos órgãos aptos ao consumo, do couro e dos resíduos usados pela indústria de rações e, principalmente, por estar associados ao rendimento de carcaça. Quando são mais 
pesados, o rendimento tende a ser menor, diminuindo o valor da carcaça (Kuss et al., 2007).

A maioria dos estudos de bovinos com diferentes condições sexuais restringe-se à avaliação do desempenho e das características da carcaça e da carne. Novilhos nãocastrados tendem a apresentar melhor eficiência alimentar e melhor ganho médio diário quando comparados aos castrados, o que é associado à produção hormomal das gônadas sexuais (Field, 1971). Outros fatores que podem influenciar as diferenças em desempenho e exigências entre bovinos com diferentes condições sexuais são os locais, a velocidade e a quantidade de tecido adiposo depositado. Gesualdi Júnior et al. (2001) ressaltam que a atividade metabólica do tecido adiposo interno é maior que a do tecido adiposo periférico, o que acarretaria aumento nos requerimentos de energia para mantença de animais com maiores depósitos de gordura. Solis et al. (1988) observaram menor exigência de mantença para vacas da raça Brahman em comparação a vacas taurinas e atribuíram o fato, em parte, à menor deposição de gordura interna e à menor atividade metabólica dos órgãos internos desses animais.

De acordo com McDonald (1989), animais não-castrados apresentam maiores valores de órgãos, intestinos e couro, em decorrência da produção hormonal. Todavia, são poucos os trabalhos que envolvem o estudo dos componentes do corpo vazio de novilhos de diferentes condições sexuais. Desse modo, avaliaram-se nesta pesquisa as características dos componentes externos e da gordura corporal de novilhos superprecoces não-castrados ou castrados de dois grupos genéticos terminados em confinamento.

\section{Material e Métodos}

O experimento foi desenvolvido no Laboratório de Bovinocultura de Corte do Departamento de Zootecnia da Universidade Federal de Santa Maria, localizado no município de Santa Maria, Rio Grande do Sul.

Foram utilizados 12 animais com idade média inicial de 12 meses, divididos em duas condições sexuais, castrados e não-castrados, e dois grupos genéticos, Charolês $(\mathrm{Ch})$ ou Nelore (Ne). O grupo Charolês foi composto por novilhos dos genótipos: $\mathrm{Ch} ; 11 / 16 \mathrm{Ch} 5 / 16 \mathrm{Ne} ; 21 / 32 \mathrm{Ch} 11 / 32 \mathrm{Ne}$; e o Nelore por animais dos genótipos: Ne; $11 / 16 \mathrm{Ne} 5 / 16 \mathrm{Ch}$; $21 / 32 \mathrm{Ne} 11 / 32 \mathrm{Ch}$, todos oriundos de mesmo rebanho, com mesmo manejo sanitário e nutricional. A orquiectomia (castração) foi realizada "a faca", pelo corte da pele e das membranas dos testículos e sua extirpação, quando os novilhos apresentavam 12 meses de idade. Os animais foram alocados individualmente em baias com $20 \mathrm{~m}^{2}$ parcialmente cobertos com piso de alvenaria provida de comedouro individualizado e bebedouro regulado por torneira-boia comum a dois boxes. Os animais foram alimentados diariamente com uma única refeição, fornecida às $8 \mathrm{~h} 30$.

O período de terminação teve duração de 116 dias, sendo que ao início do período experimental os novilhos apresentavam peso vivo médio de $267,0 \mathrm{~kg}$. Todos os animais receberam a mesma dieta ( $10 \%$ de proteína bruta), composta de silagem de milho e concentrado, que continha farelo de trigo $(96 \%)$, calcário calcítico $(3 \%)$, cloreto de sódio (1\%) e monensina sódica na dose recomendada pelo fabricante, em uma relação de volumoso:concentrado de 50:50 (base na matéria seca). A quantidade de alimento oferecido por dia foi regulada pelo consumo voluntário, procurando-se manter sobras equivalentes a $5-8 \%$ da quantidade ofertada. Para tanto, as sobras eram retiradas diariamente antes da alimentação, a fim de medir o consumo do dia anterior e ajustar a oferta do dia subseqüente.

Os animais foram pesados antes do início do período experimental, e em intervalos médios de 21 dias, até o momento do embarque para o frigorífico, sendo previamente submetidos a jejum de sólidos e líquidos por 14 horas. O momento de abate foi determinado para quando as categorias atingissem peso pré-estabelecido de $400 \mathrm{~kg}$. Em seguida, foram transportados a um frigorífico comercial cerca de $30 \mathrm{~km}$ do local do experimento e abatidos por concussão cerebral seguida de secção da veia jugular, segundo o fluxo normal do estabelecimento. Durante o abate, todas as partes do corpo do animal foram separadas e pesadas individualmente, e consistiram de: conjunto de componentes externos: cabeça, patas, orelhas, chifres (quando presentes), vassoura da cauda e couro; conjunto de órgãos vitais: pulmão, fígado, rins, coração e baço; conjunto de gorduras internas: gordura de toalete, gordura inguinal, gordura renal, gordura do coração, gordura ruminal, gordura do abomaso e gordura intestinal; conjunto do trato digestivo vazio: rúmen + retículo, omaso, abomaso, intestinos (grosso + delgado) vazios; e sangue. Antes de serem encaminhadas à câmara de resfriamento, as duas meias-carcaças foram identificadas e pesadas, obtendo-se o peso de carcaça quente. O peso de corpo vazio (PCV) foi obtido pelo somatório do peso de carcaça quente, sangue e de todos os componentes agrupados conforme citado anteriormente. Os dados foram submetidas à análise de variância pelo proc GLM. O modelo estatístico adotado foi:

$$
\mathrm{Yij}=\mu+\mathrm{C}_{\mathrm{i}}+\mathrm{GG}_{\mathrm{j}}+\left(\mathrm{C}^{*} \mathrm{GG}\right)_{\mathrm{ij}}+\mathrm{E}_{\mathrm{ijk},}
$$

em que: $\mathrm{Y}_{\mathrm{ij}}=$ variáveis dependentes; $\mu=$ média de todas as observações; $\mathrm{C}_{\mathrm{i}}=$ efeito da condição sexual de ordem $\mathrm{i}$ ( 1 = castrados e 2 = não-castrados $) ; \mathrm{GG}_{\mathrm{j}}=$ efeito do grupo genético de ordem $\mathrm{j}(1=$ Charolês e $2=$ Nelore $) ;\left(C^{*} \mathrm{GG}\right)_{\mathrm{ij}}=$

R. Bras. Zootec., v.40, n.8, p.1774-1780, 2011 
efeito da interação da condição sexual i com o grupo genético $j ; E_{i j k}=$ efeito residual aleatório. As médias foram classificadas pelo teste "F" e os parâmetros com efeito significativo para interação $(\mathrm{C} * \mathrm{GG})$ comparados pelo "teste t", a 5\% de significância através do pacote estatístico (SAS, 2001).

\section{Resultados e Discussão}

O peso de corpo vazio foi similar entre grupos genéticos e condições sexuais dos novilhos (Tabela 1), o que é influenciado principalmente pela similaridade nos pesos de abate, com valor médio de $398 \mathrm{~kg}$, o qual foi predeterminado. Neste estudo, a correlação entre essas duas variáveis foi significativa com $r=0,98$ (Tabela 5). Pacheco et al. (2005) observaram semelhança para o peso de corpo vazio entre categorias e grupos genéticos.

Similaridade também foi verificada para a relação entre o peso do corpo vazio e o peso de abate, com os valores ficando em torno de 87\%. De acordo com Owens et al. (1995) várias equações de regressão foram criadas para estimar o peso corporal vazio através do peso vivo, sendo que o mesmo correspondia de 85 a $95 \%$ do peso corporal. Trabalhos que se referem à eficiência nutricional de bovinos, como o NRC (2000), e o CNCPS (2003) tem como valor para essa relação $89,1 \%$, não diferindo quanto ao estado fisiológico do animal (castrado ou não-castrado). Nesses trabalhos, os

Tabela 1 - Pesos de abate e de corpo vazio, relação entre peso de corpo vazio e peso de abate e rendimentos de carcaça quente e fria em relação ao peso de corpo vazio (PCV)

\begin{tabular}{|c|c|c|c|}
\hline \multirow[t]{2}{*}{ Grupo genético } & \multicolumn{2}{|c|}{ Condição sexual } & \multirow[t]{2}{*}{ Média } \\
\hline & Castrados & Não-castra & \\
\hline \multicolumn{4}{|c|}{ Peso de abate, $\mathrm{kg}$} \\
\hline Charolês & 410,2 & 429,2 & 419,2 \\
\hline Nelore & 360,0 & 392,0 & 375,8 \\
\hline Média & 385,0 & 410,0 & \\
\hline \multicolumn{4}{|c|}{ Peso de corpo vazio, $\mathrm{kg}$} \\
\hline Charolês & 355,0 & 366,5 & 360,7 \\
\hline Nelore & 315,2 & 342,0 & 328,6 \\
\hline Média & 335,1 & 354,2 & \\
\hline \multicolumn{4}{|c|}{ Peso corpo vazio/Peso de abate, $\%$} \\
\hline Charolês & 86,7 & 85,5 & 86,0 \\
\hline Nelore & 87,6 & 87,2 & 87,4 \\
\hline Média & 87,1 & 86,4 & \\
\hline \multicolumn{4}{|c|}{ Rendimento de carcaça quente (\% PCV) } \\
\hline Charolês & 66,7 & 68,2 & 68,0 \\
\hline Nelore & 65,3 & 65,6 & 65,5 \\
\hline Média & 66,0 & 66,9 & \\
\hline \multicolumn{4}{|c|}{ Rendimento de carcaça fria (\% PCV) } \\
\hline Charolês & 65,1 & 66,7 & 65,9 \\
\hline Nelore & 63,8 & 64,1 & 64,0 \\
\hline Média & 64,4 & 65,4 & \\
\hline
\end{tabular}

animais são principalmente de raças britânicas, que tem composição de ganho diferente das utilizadas neste estudo. Kuss et al. (2008) observaram semelhança no rendimento de corpo vazio de novilhos não-castrados e castrados com valores de 90,83 e 91,31\%, respectivamente.

Diferença na relação entre o peso de corpo vazio e o peso de abate é relatada por Macitelli et al. (2005) ao avaliar diferentes volumosos na dieta, cana-de-açúcar, silagem de milho e pastagem de Brachiaria brizantha, com peso de corpo vazio representando 92,$1 ; 94,5$ e $94,4 \%$ do peso vivo dos animais, respectivamente, e por Alves Filho (2007), que utilizou diferentes níveis de silagem de girassol em substituição a silagem de milho na dieta de novilhos confinados. Esses resultados demonstram a influência do tipo de alimentação no rendimento do peso de corpo vazio.

Para o componente orelhas, observou-se interação significativa entre as categorias e grupos genéticos utilizados quando expresso em peso absoluto (Tabela 2). Entre os novilhos com predominância Charolês, os castrados apresentaram maiores pesos em relação aos não-castrados $(0,99$ e $0,66 \mathrm{~kg})$, respectivamente, não se observando diferença para o genótipo Nelore. Pacheco et al. (2005), com animais das categorias jovens e superjovens dos grupos genéticos $5 / 8 \mathrm{Ch} 3 / 8 \mathrm{Ne}$ e $5 / 8 \mathrm{Ne} 3 / 8 \mathrm{Ch}$, encontraram interação para essa mesma característica quando expressa em relação ao peso de corpo vazio, observando maiores pesos para novilhos $5 / 8 \mathrm{Ne} 3 / 8 \mathrm{Ch}$ da categoria jovem.

Nos novilhos castrados, o peso de cabeça foi maior quando expresso em relação ao peso de abate, com valores de 3,29 e 3,15\% para animais castrados e não-castrados, respectivamente. Ao estudar o desenvolvimento relativo dos componentes do corpo vazio de quatro raças, a partir dos coeficientes de alometria, Jorge \& Fontes (2001) observaram que a cabeça apresentou coeficiente menor que 1, ou seja, o desenvolvimento desta parte é inferior ao do peso de corpo vazio, refletindo maturidade mais precoce deste componente. Isso pode sugerir que os animais castrados atingiram a maturidade mais precocemente.

O peso do couro diferiu entre os grupos genéticos estudados, tendo os novilhos Nelore apresentado maiores pesos quando este foi expresso em relação aos pesos de corpo vazio e de abate. Maior peso de couro ajustado aos pesos de abate e de corpo vazio a favor de animais zebuínos é reportado por Pacheco et al. (2005), que trabalharam com novilhos dos grupos genéticos $5 / 8 \mathrm{Ch} 3 / 8 \mathrm{Ne}$ e $5 / 8 \mathrm{Ne} 3 / 8 \mathrm{Ch}$, atribuindo tal superioridade ao maior desenvolvimento da barbela e do cupim, assim como aos maiores comprimentos de braços e pernas dos animais. Este fato é resultado da adaptação dos zebuínos a climas quentes, apresentando maior superfície corporal e o couro com maior mobilidade 
Tabela 2 - Componentes externos, em peso absoluto e porcentagem do peso de corpo vazio (PCV) e de peso de abate (PAB)

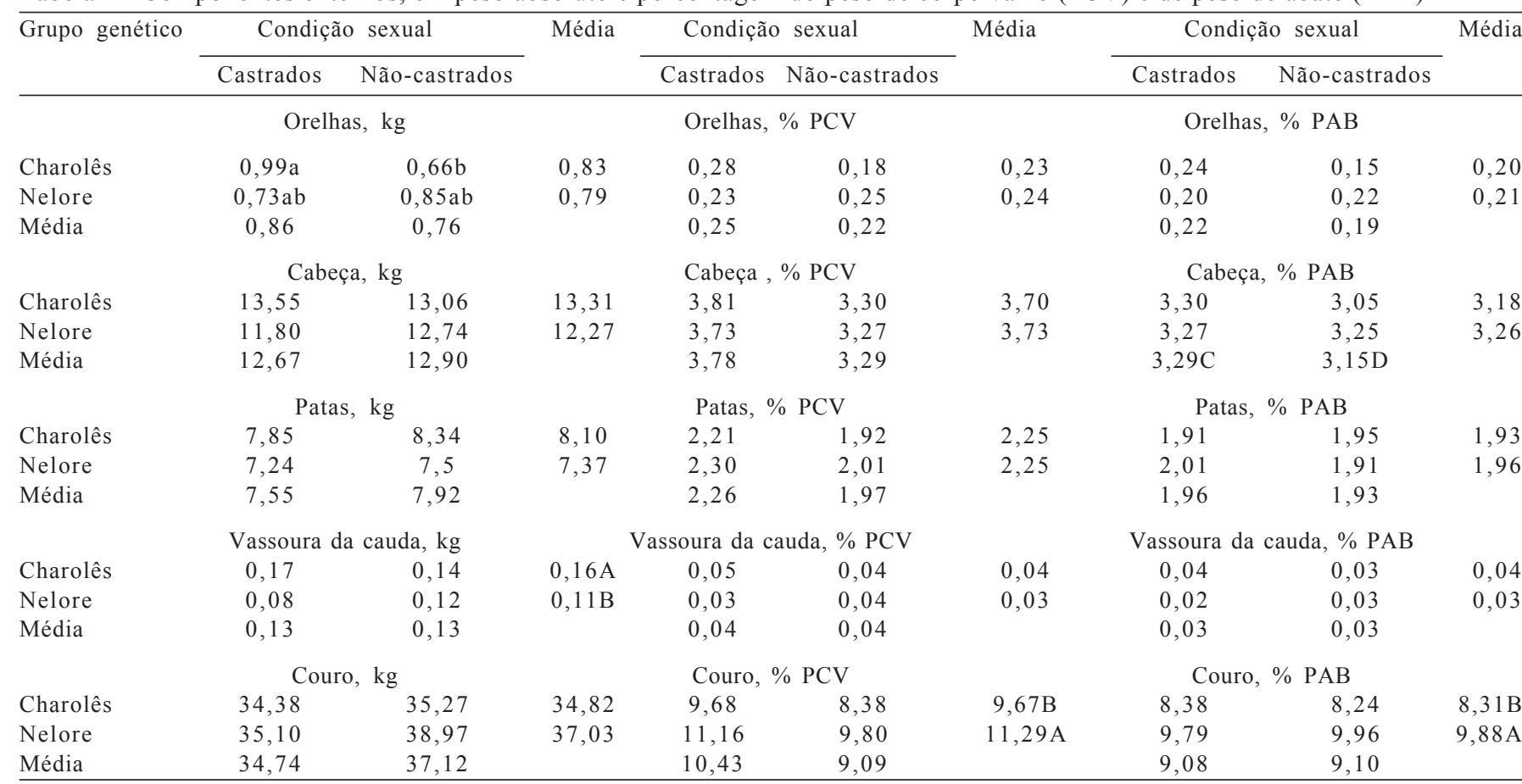

A, B - Médias seguidas por letras maiúsculas diferentes na coluna para a mesma característica, diferem $(P<0,05)$ pelo teste $\mathrm{F}$.

C, D - Médias seguidas por letras maiúsculas diferentes na linha para a mesma característica, diferem $(\mathrm{P}<0,05)$ pelo teste $\mathrm{F}$.

$\mathrm{a}, \mathrm{b},-$ Médias seguidas por letras minúsculas diferentes para a mesma característica diferem $(\mathrm{P}<0,05)$ pelo teste $\mathrm{t}$.

e menor espessura (McDowell, 1974). Preston \& Willis (1974) e Berg \& Buterfield (1976) relatam que animais taurinos apresentam maior peso de couro em virtude da maior espessura deste em relação aos animais zebuínos.

O couro é um dos subprodutos do abate de maior interesse para os frigoríficos, em virtude do valor que pode ser agregado ao mesmo após o seu beneficiamento e processamento, sendo utilizado principalmente em indústrias calçadistas e de vestuário. A participação desse componente variou de 8,38 a $11,16 \%$ do peso de corpo vazio, similar aos valores citados por Restle et al. (2005), Pacheco et al (2005) e Backes et al. (2006).

Ainda com relação aos grupos genéticos, observou-se diferença para o peso da vassoura da cauda em peso absoluto, com valores de 0,16 e $0,11 \mathrm{~kg}$ para os novilhos Charolês e Nelore, respectivamente. Com animais mestiços de terceira geração entre as raças Charolês e Nelore, Pacheco et al. (2005), não observaram diferença para esta característica entre os genótipos avaliados em seu estudo.

Quando avaliada em relação aos pesos de corpo vazio e de abate, a gordura dos intestinos apresentou diferença entre as condições sexuais dos novilhos, com superioridade para os castrados (Tabela 3). Esse fato pode estar relacionado à condição sexual, já que animais castrados atingem a maturidade mais precocemente e completam o seu crescimento muscular mais rápido, passando a depositar tecido adiposo mais rapidamente que animais não-castrados que apresentam um maior desenvolvimento do tecido muscular pela ação hormonal.

Ainda com relação aos diferentes tipos de gordura, pode ser observado que tanto em valores absolutos, como em relação aos pesos de corpo vazio e peso de abate, na maioria delas os animais castrados foram numericamente superiores. Segundo Owens et al. (1993), a gordura interna é a primeira a se depositar no animal, sendo seguida pela gordura intermuscular e por último a gordura intramuscular (marmoreio). Para Jones et al. (1985), a deposição de gordura nas partes não integrantes da carcaça aumenta em taxas semelhantes à gordura da carcaça.

Segundo Di Marco (1998), a gordura visceral acumulada é um desperdício que não agrega valor à carcaça, além de afetar a eficiência do animal em converter o alimento, sendo inevitável o seu acúmulo quando o animal avança em seu grau de terminação. O maior aúmulo de gordura interna acarreta em maiores exigências de energia para mantença (Owens et al., 1995). Gesualdi Júnior et al. (2001) ressaltam que a atividade metabólica do tecido adiposo interno seja maior que a do tecido adiposo periférico, o que acarretaria em aumentos nos requerimentos de energia para mantença de animais com maiores depósitos de gordura. Esse fato ajuda a explicar o melhor ganho médio diário dos animais não-castrados em relação aos castrados, 1,20 versus 
Tabela 3 - Gorduras, em peso absoluto e em porcentagem do peso de corpo vazio (PCV) e do peso de abate (PAB)

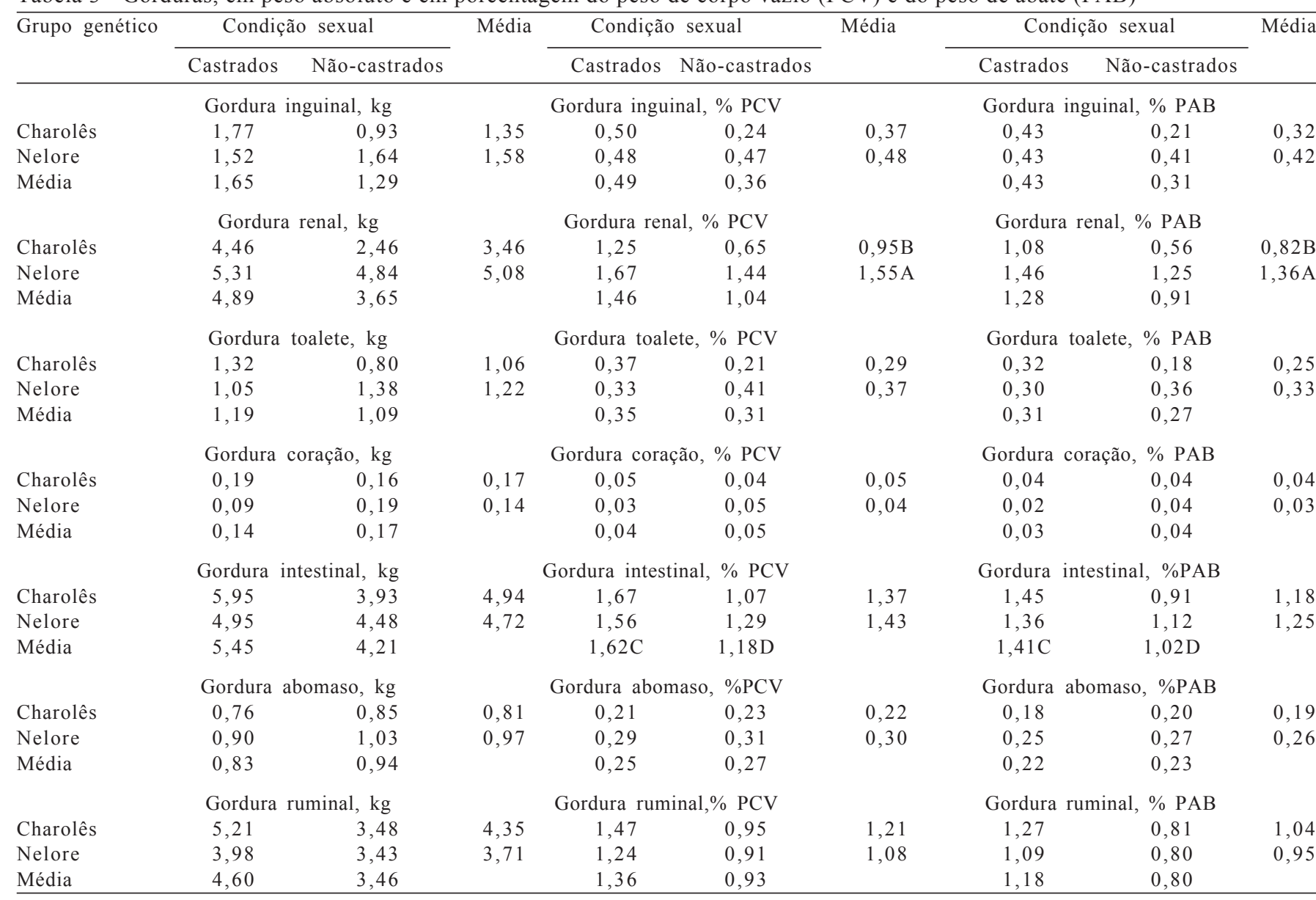

A, B - Médias seguidas por letras maiúsculas diferentes na coluna para a mesma característica diferem $(\mathrm{P}<0,05)$ pelo teste $\mathrm{F}$.

C, D - Médias seguidas por letras maiúsculas diferentes na linha para a mesma característica diferem $(\mathrm{P}<0,05)$ pelo teste $\mathrm{F}$.

$1,05 \mathrm{~kg}$, respectivamente. Conforme Kuss et al. (2007), a quantidade de tecido adiposo depositado no corpo dos animais condiciona sua eficiência alimentar, pois este tecido, em comparação ao tecido muscular, requer maior quantidade de nutrientes para sua deposição.

Novilhos com predominância Nelore no genótipo apresentaram maiores valores para a gordura renal quando esta foi ajustada em relação aos pesos de corpo vazio. Pacheco et al. (2005) observaram maior deposição de gordura renal em novilhos com predomínio Charolês no genótipo em todas formas de expressão.

Para o total de gordura interna (Tabela 4), houve diferença significativa entre as condições sexuais, com superioridade dos animais castrados em relação aos nãocastrados, com valores de 5,58 e $5,15 \%$ do peso de corpo vazio e 4,86 e 3,60\% quando expressa em relação ao peso de abate, respectivamente. Embora não ocorrido diferença significativa para o peso das gorduras internas expressas em diferentes formas (Tabela 3), numericamente os animais castrados apresentaram uma superioridade para o peso das gorduras internas, o que deve estar relacionado ao seu estádio de desenvolvimento mais avançado, onde os mesmos já haviam completado seu crescimento muscular, passando a aumentar os seus depósitos de gordura. Roblein et al. (1974) relatam que o coeficiente alométrico para o total de gordura depositada é próximo a dois, o que indica que o desenvolvimento do tecido adiposo é de maturidade mais tardia. Trabalhando com novilhos de diferentes condições sexuais, Kuss et al. (2008) verificaram, ao ajustar a gordura interna em relação aos pesos de corpo vazio e de abate, maior deposição dessa gordura em animais castrados.

Quanto ao conjunto de componentes externos, os novilhos com predominância Nelore no genótipo foram superiores quando esses foram ajustados em relação ao peso de abate, influenciados principalmente pela superioridade no peso do couro. A correlação entre o peso do couro e o conjunto dos componentes externos foi 0,94 (Tabela 5). Pacheco et al. (2005) relatam maiores valores ajustados para os pesos de abate e de corpo vazio no conjunto de componentes externos em favor de animais zebuínos em ralação aos taurinos. 
Kuss et al. (2007) estudando a terminação de vacas de descarte abatidas com diferentes pesos observaram aumento no conjunto de componentes externos quando o peso de abate se elevou de 465 para $566 \mathrm{~kg}$ e quando expressos em relação aos pesos de corpo vazio e de abate, verificaram decréscimo na participação desses componentes com peso de abate mais elevado. Os mesmos autores ressaltam que as diferenças observadas para consumo alimentar e rendimentos de carcaça de bovinos Bos indicus e Bos taurus possam estar relacionadas às características e ao peso dos tecidos de revestimento e membros.

Dentre os constituintes do corpo vazio, o peso final dos animais esteve positivamente correlacionado com os pesos do couro, da cabeça, das patas e do conjunto dos componentes externos (Tabela 5). Kuss et al (2007) encontraram correlação significativa entre o conjunto de componentes externos com o peso de abate $(r=0,55 ; \mathrm{P}=0,0057)$.

Os rendimentos de carcaça quente ou fria não apresentaram correlação significativa com nenhum dos componentes do corpo vazio deste estudo, porém ambas foram negativamente correlacionadas ao conjunto de componentes externos, o que indica que maior participação desses acarreta em menores rendimentos de carcaça.

Pacheco et al. (2006) observaram correlação negativa do total de gorduras internas quando ajustada para o peso de corpo vazio com os rendimentos de carcaças quente $(\mathrm{r}=-0,68 ; \mathrm{P}=0,001)$ e fria $(\mathrm{r}=-0,76 ; \mathrm{P}=0,001)$, o que segundo os autores é uma informação muito importante, pois maiores períodos de confinamento determinam mudanças nas composições de ganho de peso, o que causa excesso de gordura na carcaça, que além de representar maiores gastos energéticos, prejudica o rendimento de carcaça e, consequentemente, a lucratividade.

Galvão et al. (1991) relatam que menores rendimentos de carcaça podem estar associados com o aumento da gordura visceral, que se contrapõem ao menor crescimento relativo das vísceras com o avanço da maturidade do animal. Correlação positiva entre gorduras internas e rendimento de carcaça é relatada por Kuss et al. (2007). Os mesmos autores observaram que a gordura interna correlacionou-se com o ganho médio diário de peso $(\mathrm{r}=0,45 ; \mathrm{P}=0,0274)$. Neste estudo, o único componente do corpo vazio que se correlacionou com essa variável foi o peso da cabeça $(\mathrm{r}=0,77)$.

Tabela 4 - Conjuntos dos componentes externos e das gorduras, em peso absoluto e em porcentagem do corpo vazio (PCV) e do peso de abate $(\mathrm{PAB})$

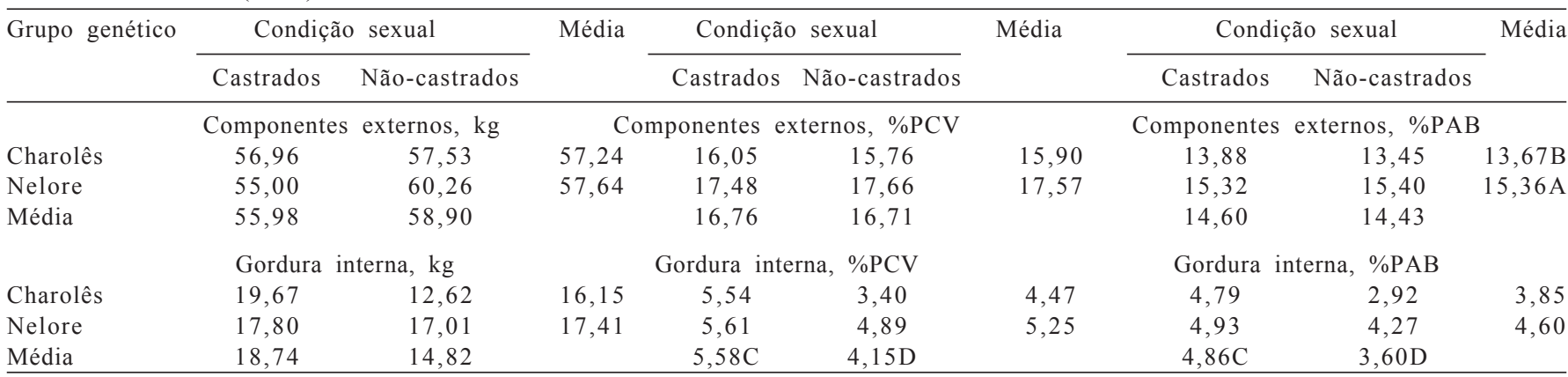

A, B - Médias seguidas por letras maiúsculas diferentes na coluna para a mesma característica diferem $(\mathrm{P}<0,05)$ pelo teste $\mathrm{F}$.

C, D - Médias seguidas por letras maiúsculas diferentes na linha para a mesma característica diferem $(\mathrm{P}<0,05)$ pelo teste $\mathrm{F}$.

Tabela 5 - Coeficientes de correlação de Pearson entre as variáveis pesos inicial, de abate e de corpo vazio (PCV), relação entre $\mathrm{PCV} / \mathrm{PAB}$, rendimentos de carcaça quente (RCQ) e fria (RCF), couro, cabeça, patas, componentes externos, gorduras de toalete e interna e ganho médio diário (GMD) de novilhos superprecoces

\begin{tabular}{|c|c|c|c|c|c|c|c|c|c|c|c|c|}
\hline Variável & PAB & $\mathrm{PCV}$ & $\mathrm{PCV} / \mathrm{PAB}$ & RCQ & $\mathrm{RCF}$ & Couro & Cabeça & Patas & $\begin{array}{l}\text { Comp. } \\
\text { externos }\end{array}$ & $\begin{array}{c}\text { Gordura de } \\
\text { toalete }\end{array}$ & $\begin{array}{l}\text { Gordura } \\
\text { interna }\end{array}$ & GMD \\
\hline Peso inicial & $0,97^{*}$ & $0,95^{*}$ & $-0,11$ & 0,34 & 0,36 & 0,31 & $0,92^{*}$ & $0,78^{*}$ & $0,58^{*}$ & $-0,17$ & 0,34 & $0,79^{*}$ \\
\hline Peso ao abate (PAB) & & $0,98^{*}$ & $-0,09^{*}$ & 0,41 & 0,43 & $0,35^{*}$ & $0,91^{*}$ & $0,73^{*}$ & $0,60^{*}$ & $-0,07$ & 0,30 & $0,91^{*}$ \\
\hline $\mathrm{PCV} / \mathrm{PAB}$ & & & & 0,35 & 0,35 & 0,19 & 0,01 & $-0,40$ & 0,09 & 0,57 & $0,60^{*}$ & $-0,05$ \\
\hline RCQ & & & & & $0,99^{*}$ & $-0,41$ & 0,24 & $-0,01$ & $-0,29$ & 0,09 & 0,05 & 0,46 \\
\hline $\mathrm{RCF}$ & & & & & & $-0,37$ & 0,25 & 0,01 & $-0,24$ & 0,09 & 0,04 & 0,50 \\
\hline Patas & & & & & & & & & 0,56 & $-0,58^{*}$ & $-0,07$ & 0,55 \\
\hline Componentes externos & & & & & & & & & & 0,14 & 0,46 & 0,58 \\
\hline Gordura de toalete & & & & & & & & & & & 0,54 & 0,09 \\
\hline Gordura interna & & & & & & & & & & & & 0,18 \\
\hline
\end{tabular}




\section{Conclusões}

A condição sexual de novilhos com predominância genética Charolês ou Nelore não influencia o peso de corpo vazio. Novilhos com predominância Nelore apresentam maior participação dos componentes externos, devido principalmente ao maior peso do couro.

\section{Referências}

ALVES FILHO, D.C. Características pós-abate de novilhos terminados com silagem de girassol (Helianthus annuus L.). 2007. 140f. Tese (Doutorado em Zootecnia) - Universidade Ferderal do Rio Grande do Sul, Porto Alegre.

BACKES, A.A.; PAULINO, M.F.; ALVES, D.D. et al. Tamanho relativo dos órgãos internos e do trato gastrintestinal de bovinos zebu e mestiços leiteiros em sistema de recria. Ciência Rural, v.36, n.2, p.594-598, 2006.

BERG, R.T.; BUTTERFIELD, R.M. New concepts of cattle growth. Sydney: Sydney University Press, 1976. 240p.

CNCPS. Version 5.0. The net carbohydrate and protein system for evaluating herd nutrition and nutrient excretion, Model Documentation. Cornell: Cornell University, Department of Animal Science, 2003. 292p.

DI MARCO, O.N. Crescimiento de vacunos para carne. 1.ed. Mar del Plata: Balcarcwe, 1998. 246p.

FIELD, R.A. Effect of castration and meat quality and quantitaty. Journal of Animal Science, v.32, n.5, p.849-858, 1971.

GALVÃO, J.G.; FONTES, C.A.A.; PIRES, C.C. et al. Características e composição da carcaça de bovinos não castrados, abatidos em três estágios de maturidade (estudo II) de três grupos raciais. Revista da Sociedade Brasileira de Zootecnia, v.20, n.5, p.502-512, 1991.

GESUALDI JÚNIOR, A.; VELOSO, C.M.; PAULINO, M.F. et al. Níveis de concentrado na dieta de bovinos $F_{1}$ Limousin x Nelore: peso dos órgãos internos e trato digestivo. Revista Brasileira de Zootecnia, v.30, n.6, p.1866-1871, 2001.

JONES, S.D.M.; ROMPALA, R.E.; JEREMIAH, L.E. Growth and composition of the empty body in steers of different maturity types fed concentrate of forage diets. Journal of Animal Science, v.60, n.2, p.427-433, 1985.

JORGE, A.M.; FONTES, C.A.A. Desenvolvimento relativo das partes do corpo de zebuínos de quatro raças. Ciência Rural, v.31, n.5, p.857-861, 2001.

KUSS, F.; RESTLE, J.; BROONDANI, I.L. et al. Componentes externos do corpo e gordura de descarte em vacas mestiças
Charolês x Nelore abatidas com diferentes pesos. Revista Brasileira de Zootecnia, v.36, n.4, p.865-873, 2007.

KUSS, F.; BARCELlOS, J.O.J.; LOPEZ, J. et al. Componentes não-integrantes da carcaça de novilhos não-castrados ou castrados em confinamento e abatidos aos 16 ou 26 meses de idade. Revista Brasileira de Zootecnia, v.37, n.10, p.1829-1836, 2008 .

MACITELLI, F.; BERCHIELLI, T.T.; SILVEIRA, R.N. et al. Biometria da carcaça e peso de vísceras e órgãos internos de bovinos mestiços alimentados com diferentes volumosos e fontes protéicas. Revista Brasileira de Zootecnia, v.34, n.5, p.1751-1762, 2005.

McDONALD, L. Endocrinologia veterinária, reproduccion. 4.ed. México: Interamericana. MC. RC. Grow. Hill, 1989. 261p.

McDOWELL, R.E. Iproviment of livestock production in worm climate. San Francisco, W.H. Freeman Co, 1974. 436p.

NATIONAL RESEARCH COUNCIL - NRC. Nutrient requirements of beef cattle. 7.ed. Washington: D.C.: National Academy Science, 2000. 232p.

OWENS, F.N.; DUBESKI, P.; HANSON, C.F. Factors that alter the growth and development of ruminants. Journal of Animal Science, v.71, n.6, p.3138-3150, 1993.

OWENS, F.N.; GILL, D.R.; SECRIST, D.S. et al. Review of some aspects of growth and development of feedlot cattle. Journal of Animal Science, v.73, p.3152-3172, 1995.

PACHECO, P.S.; RESTLE, J.; SILVA, J.H.S. et al. Características das partes do corpo não-integrantes da carcaça de novilhos jovens e superjovens de diferentes grupos genéticos. Revista Brasileira de Zootecnia, v.34, n.5, p.1678-1690, 2005.

PRESTON, T.R.; WILLIS, M.B. Intensive beef cattle production. 2.ed. Oxford: Pergamon Press, 1974. 546p.

PACHECO, P.S.; RESTLE, J.; SILVA, J.H.S. et al. Relações entre componentes do corpo vazio e rendimentos de carcaça de novilhos de corte. Ciência Animal Brasileira, v.7, n.2, p.107-113, 2006.

RESTle, J.; MENEZES, L.F.G.; ARBOITTE, M.Z. et al. Características das partes não-integrantes da carcaça de novilhos 5/8 Nelore 3/8 Charolês abatidos em três estádios de desenvolvimento. Revista Brasileira de Zootecnia, v.34, n.4, p.1339-1348, 2005.

ROBLEIN, J.; GEAY, Y.; BÉRANGER, C. Croissance relative dés différents tissues, organs at regions corporelles des taurillons frisons, durant la phase d'engraissement de 9 a 15 mois. Annales de Zootechnie, v.23, p.313-323, 1974.

STATISTICAL ANALYSIS SYSTEM - SAS. SAS/STAT. User's guide: statistics, versão 8.1. 4.ed., v.2. Cary: SAS Institute, 2001. (CD-ROM)

SOLIS, J.C.; BYERS, F.M.; SCHELLING, G.T. et al. Maintenance requirements and energetic efficiency of cows of different breed types. Journal of Animal Science, v.66, p.764-773, 1988. 